\title{
OFICINAS DE IDENTIDADE NA ADOLESCÊNCIA: AS RELAÇÕES ENTRE IDENTIDADE PSICOSSOCIAL E INSERÇÃO SOCIAL PELA VIA DA EDUCAÇÃO
}

\author{
TALLERES DE IDENTIDAD EN LA ADOLESCENCIA: LAS RELACIONES ENTRE \\ IDENTIDAD PSICOSOCIAL E INSERCIÓN SOCIAL POR LA VÍA DE LA \\ EDUCACIÓN
}

\begin{abstract}
IDENTITY WORKSHOPS IN ADOLESCENCE: THE RELATIONSHIP BETWEEN PSYCHOSOCIAL IDENTITY AND SOCIAL INTEGRATION THROUGH EDUCATION
\end{abstract}

\author{
Jaisso VAUTERO ${ }^{1}$
}

RESUMO: Trata-se de um trabalho a respeito do impacto sobre a identidade do aluno adolescente dos estados de incerteza instalados neste momento de vida que remetem a uma série de determinantes sociais, mas com interesse especial no processo de inserção e ascensão social através da educação. Ele foca uma experiência denominada Oficinas de identidade na adolescência, realizada através de grupos de discussão conduzidos por estagiário de psicologia. Os resultados apontam para o desejo do adolescente em subir na vida, suas perspectivas sobre mercado de trabalho, as relações entre trabalho e estudo e a necessidade independência financeira. As conclusões se concentram em torno das diferentes funções que o ensino formal assume para diferentes contextos, e no papel da educação na construção de identidades.

PALAVRAS-CHAVE: Educação. Universidade. Identidade. Inserção e ascensão social.

RESUMEN: Se trata de un trabajo acerca del impacto sobre la identidad del alumno adolescente de los estados de incertidumbre asociados a este momento de vida que remiten a determinantes sociales, pero con interés especial en el proceso de inserción social por la vía de la educación. El trabajo observa a una experiencia denominada Talleres de identidad en la adolescencia, realizada a través de grupos de discusión conducidos por pasantes de psicología. Los resultados apuntan al deseo del adolescente en subir en la vida, sus perspectivas sobre el mercado de trabajo, las relaciones entre trabajo y estudio y la necesidad de independencia financiera. Las conclusiones se concentran en torno a las diferentes funciones que la enseñanza formal asume para diferentes contextos, y en el papel de la educación en la construcción de identidades.

PALABRAS CLAVE: Educación. Universidad. Identidad. Inserción y ascensión social.

ABSTRACT: It is a work about the impact of uncertainty on adolescents' students identity, which refers to several social determinants. The work has a special interest in the process of

${ }^{1}$ Universidade Federal de Santa Maria (UFSM), Santa Maria - RS - Brasil. Mestre em Psicologia (UFSM, 2011) e Doutorando em Psicologia aplicada (Universidade do Minho). ORCID: https://orcid.org/0000-00030377-1145. E-mail: jaissorv@gmail.com. 
integration and social mobility through education. It focuses on an experiment called Identity workshops in adolescence, accomplished through discussion groups conducted by psychology trainees. The results point to the adolescent's needs to go ahead in their careers, their perspectives about labor market, the relationship between work study and the need for financial independence. The conclusions are concentrated around the different functions that formal education takes for different contexts, and the role of education in the construction of identities.

KEYWORDS: Education. University. Identity, Social insertion. Social mobility.

\section{Introdução}

O trabalho de pesquisa foca uma experiência denominada Oficinas de Identidade na Adolescência, com ênfase em questões sobre universidade, inserção e ascensão social. Considerando a adolescência como um período em que as questões identitárias estão em relevo, surge nesse período a necessidade de desenvolver um processo autônomo de inserção e ascensão social, onde faz parte deste desafio a definição da identidade ocupacional (ERIKSON, 1976). O acesso à universidade, como parte do processo, é uma via de inserção e ascensão social, porém, a valorização da educação pelo mercado do trabalho e a disparidade da renda com relação nível de estudo deixam claro o papel da universidade como promotor de inserção e ascensão social (VAUTERO et al., 2017).

Seguindo essa perspectiva, a educação superior vem acompanhando as transformações ocorridas na sociedade brasileira, sendo demandada por um número cada vez maior de pessoas. $\mathrm{O}$ atual panorama do ensino superior no país mostra que o mesmo se encontra em expansão, ainda que em ritmo menos nos últimos anos. O número de vagas existentes é um bom indicativo desse crescimento: passaram de 430 mil em 1985 para 3,8 milhões em 2007 e 8,2 milhões em 2016 (INEP, 2016). Mesmo assim, o ensino superior brasileiro continua sendo um direito exercido por poucos, alcançando apenas cerca de $15 \%$ da população (IBGE, 2016).

Boaventura de Souza Santos (2005) questiona o lugar da universidade no século XXI, colocando-a no limite entre a função social, desenvolvimento e ascensão social do aluno, e uma lógica de mercado, voltada para a produção de conhecimento tecno-científico. Cabe então algum questionamento quanto a este limite, operacionalizado por trabalhos que habilitem aos atores sociais envolvidos reflexão e crítica. Motivo pelo qual esta atividade, Oficinas de Identidade na Adolescência, foi escolhida como foco deste trabalho de pesquisa.

Estas oficinas são na realidade uma atividade de estágio que também apresenta algumas características de extensão, vinculada ao curso de Psicologia de uma universidade do 
sul do Brasil 1) em parceria com a prefeitura municipal de Jaguari/RS e da rede estadual de ensino da mesma cidade e, 2) com uma escola técnica federal. O seu objetivo é trabalhar em torno das dúvidas e incertezas em relação ao ingresso no ensino superior, enquanto via de inserção e ascensão social, tomando-as como subsidiárias à problemáticas identitárias do adolescente. A pesquisa se dá em torno destas oficinas, e tem como objetivo ampliar a compreensão sobre as problemáticas identitárias dos participantes nos grupos, com foco especial no processo de inserção e ascensão social através da educação, tomando-o como parte do processo de formação identitária. Considera ainda toda a riqueza do estágio, mas seu foco imediato está sobre as supervisões de estágio, baseada em uma participação democrática com elementos semelhantes à pesquisa ação. A dinâmica destas reuniões também se pauta pela proposta de grupos de discussão (CALLEJO, 2001), não apresentando uma estrutura prédefinida, mas que se define ao longo dos encontros.

\section{Inserção e ascensão social: definições preliminares}

Os conceitos de inserção e ascensão social são considerados em conjunto, uma vez que pressupõe a entrada (inserção) do aluno em um novo grupo social, o portador de diploma superior, e a mobilidade social (ascensão) que implica a melhora das condições de vida do aluno no futuro, o que transcende a estratificação em classes sociais apenas por critérios econômicos. Em resumo, a busca de ascensão implica uma elevação de nível, no caso, nível socioeconômico, já inserção aponta a entrada em determinado lócus. Em ambas as situações há um movimento de ruptura, interessa saber as relações da educação e da identidade com essas rupturas.

A movimentação social, mesmo que definida aqui como inserção e ascensão no espaço social é por demais ampla; interessa ao estudo o movimento em torno de um aspecto principal, no caso, a educação. Trabalhos como o de Schultz (1973) colocam a educação como responsável pelo crescimento da economia que não se explica apenas pelo capital econômico: "De forma simplificada, a educação é vista como um investimento que eleva a produtividade e os lucros dos trabalhadores, além de impulsionar o desenvolvimento econômico" (LEMOS; PINTO; DUBEUX, 2009, p. 371). O papel da educação na inserção e ascensão social já é senso comum, foco de políticas públicas que visam desenvolvimento social, esperança, por vezes messiânica das famílias e ponto central no "posicionamento socioeconômico das pessoas na hierarquia social” (PASTORE; SILVA, 2000, p. 40). 


\section{Mobilidade social no Brasil}

A ascensão social como sinônimo de mobilidade social não é uma temática nova. Tampouco a mobilidade social face à educação é temática recente, como pode ser visto nos estudos já clássicos de Blau e Duncan (1967) Lipset e Bendix (1959), e até mesmo Bourdieu (2007), o qual supera o conceito de classe e adota o de estratificação social. Estudos sobre o tema no Brasil mostram que até meados da década de 70 o Brasil é marcado por um campo social móvel e ascendente (PASTORE; SILVA, 2000). As décadas de 1940 e 1950 se destacam pela industrialização do país e aumento do êxodo rural. Na década de 1970, Pastore (1993, 2000) constata a presença de ascensão social em toda sociedade, porém de curto alcance e o aumento das diferenças (PASTORE; HALLER, 1993, p. 31-32).

Os dados atuais sobre mobilidade, considerando estratificação social baseada unicamente na renda apontam um cenário diferente daquele observado na década de 50 do século passado. Houve diminuição da população abaixo da linha da pobreza (NERY, 2007), contudo após anos de queda vem mostrando um aumento preocupante, apenas de 2016 para 2017 subiu de 25,7\% para 26,5\% (IBGE, 2019). O nível de emprego, que apresentou queda até 2014, volta a crescer nos últimos anos (IBGE, 2019B). Não é possível avaliar o momento com precisão, porém observa-se um cenário de mobilidade social ascendente em intervalos de longo prazo. Entretanto esses avanços podem estar comprometidos nos próximos anos, destacando mais ainda a necessidade de atenção e investimento na formação da população (GONÇALVES; SILVEIRA NETO, 2013).

\section{A mobilidade combalida}

Utilizar apenas a mobilidade para falar sobre a ascensão social acaba por focar o estudo em fatores limitados, cabe perguntar se existiriam outras forças operando no processo de ascensão social. Nas metodologias dos estudos clássicos sobre o tema foram utilizados critérios como ocupação e renda. Ainda parece estar embutido nestes estudos o entendimento de que o movimento é mecânico, que escolaridade representa ascensão social, e na simplicidade da fórmula bastaria o investimento em educação, pessoal e governamental, como garantia de melhoria do status social.

Bourdieu considera como esse sobre a mobilidade social acabam por criar uma "elaboração falsamente erudita, reduzindo o universo social a um continuum de estratos abstratos (upper midle class, lower midle class, etc.)" (BOURDIEU, 2007, p. 115). Para ele, a 
projeção sobre um único eixo reduz as diferentes espécies de capital a um padrão único, o que remete à questão de classe. Ainda de acordo com o autor, a classe social não é definida por uma propriedade, nem por uma soma de propriedades: "mas pela estrutura das relações entre todas as propriedades pertinentes que confere seu valor próprio a cada uma delas e aos efeitos que ela exerce sobre as práticas” (BOURDIEU, 2007, p. 101).

Quanto às diferentes espécies de capital cabe observar que, do ponto de vista de Bourdieu, o capital não se reduziria apenas ao capital econômico, considera a existência de um capital econômico, capital cultural e capital social, apenas o capital econômico remete ao poder econômico, o capital cultural constitui "o elemento da bagagem familiar que teria o maior impacto na definição do destino escolar" (NOGUEIRA, 2002, p. 21).

\section{Educação, classe e reprodução}

O que parece ser mais importante na concepção de Bourdieu é a negação da neutralidade da educação; a escola estaria a serviço de determinada classe, ou seria criada para esta classe, lidando com códigos sociais muito específicos, melhor traduzidos e adaptados pela classe que os cria, distanciando outras camadas sociais da possibilidade de compreensão. Nesse sentido, as diferentes Ações Pedagógicas que se exercem numa formação social colaboram harmoniosamente para a reprodução de um capital cultural concebido como uma propriedade indivisa de toda a "sociedade". Na realidade, devido ao fato de que elas correspondam aos interesses materiais e, simbólicos de grupos ou classes (BOURDIEU; PASSERON, 1992, p. 25).

O ponto central da compreensão deste trecho não está apenas no entendimento de que existem forças de dominação, mas que a classe tende a transmitir sua cultura, internamente, gerando a reprodução da própria classe. O conceito de habitus, melhor trabalhado por Bourideu em A Distinção (2007), colabora no entendimento; o habitus estaria na relação daquele que se encontra na classe social e o modo como funcionaria uma sociedade de classes. É o modo com indivíduo vive elementos de sua classe a partir de um passado familiar e da classe, elementos desta que ele interioriza (D’ÁVILA, 1998).

\section{Inserção e ascensão social e identidade}

A inserção e ascensão se contrapõe por vezes ao habitus da classe, é um movimento ativo que pressupõe ruptura, interessa a este trabalho os modos de como isso se processa. $\mathrm{Na}$ 
pista do que ocorre, é interessante questionar se as expectativas alimentadoras de um investimento educacional para determinados grupos não dependem apenas de um habitus, mas de um processo bem mais complexo de formação de uma identidade (D’ÁVILA, 1998). Isto introduz a temática identitária em um assunto que até agora tinha sido abordado pela via de uma sociologia da educação e questões de macroeconomia. A identidade passa a ter relevância ao falar de inserção e ascensão social quando é trazida à baila a ideia de trajetória. DUBAR (1997) abordou a temática ocupacional considerando a trajetória individual e as questões identitárias; tomou a problemática das trajetórias que mostram deslocamentos sociais (DUBAR, 1998), dentro do que foi considerado aqui como inserção e ascensão social. Define a distinção básica entre uma concepção de identidade constituída na base de sobredeterminações em geral sociais e uma identidade biográfica, subjetiva. Considera as duas posturas inconciliáveis, e reconhece várias tentativas de superar o essencialismo de uma identidade pessoal preestabelecida e o relativismo das categorizações sociais diversas, estruturando identidades biográficas ilusórias (DUBAR, 1998). Como forma de ultrapassar estas perspectivas elenca autores como Anselm Strauss (1999), e cita uma série de pesquisas que buscam relacionar trajetórias subjetivas com mundos vividos. Adota para isso uma perspectiva que pode ser considerada relacional, visto que se instala e pensa estas trajetórias como uma articulação (DUBAR, 1998). As possibilidades de o indivíduo romper com identidades precedentes que o inscreviam em determinado lócus social se daria nestas articulações "entre os sistemas de acção que propõem identidades virtuais e as 'trajectórias vividas' no interior das quais se forjam as identidades "reais' a que aderem os indivíduos" (DUBAR, 1997, p. 91).

Para o autor a construção da identidade passa a influir diretamente sobre as perspectivas de inserção e ascensão social de um aluno, quando, na perspectiva de Dubar, for analisada a diferença que se instala entre identidade herdada e identidade visada; hiato que necessariamente cria uma ruptura ou abandono de identidades que se formaram, temporárias ou não, visto que o foco final do trabalho recai sobre o adolescente, este em constante reencenação identitária. Este último termo remete diretamente à perspectiva de Erikson que vê a adolescência como o momento de construção ou delineação da identidade de um indivíduo, e que não se dá diretamente, mas por identidades que vão sendo integradas em um conjunto de papéis (ERIKSON, 1976, p. 212). Falar de trajetórias que realizam rupturas implica entender que forças atuam sobre o indivíduo no sentido de promover uma efetiva inserção social e real ascensão. 
A educação, cotada aqui como foco central nas modificações destas trajetórias, implica, entre outras coisas, que no contexto educacional surjam situações capazes de gerar perspectivas de projetos futuros. A identificação com possibilidades de futuros profissionais, porém, não se constrói apenas nas relações escolares, mas pelas visto que "um indivíduo, desde a infância, herda uma identidade sexual, mas também uma identidade étnica e uma identidade de classe social que são as dos seus pais" (DUBAR, 2007, p. 95).

Na relação do adolescente com seus outros significativos (MEAD, 1931) e, em geral, com a sua comunidade, sob as quais é construída a identidade, as perspectivas de futuro profissional envolvem dúvidas e incertezas. As oficinas de identidade sobre as quais esta pesquisa busca conhecer ligam a problemáticas identitária à inserção e ascensão social através da educação. Logo, não está na pauta das oficinas abordar a questão pela via ocupacional apenas, mas considerar elementos da identidade dos adolescentes participantes.

\section{Metodologia}

Trata-se de uma pesquisa que tem como principal objetivo conseguir informações acerca de um problema, tentando descobrir novos fenômenos ou relações entre eles (GIL, 1999) configura uma pesquisa exploratória e tem por finalidade esclarecer, modificar conceitos e ideias.

Participaram do estudo 15 estagiários do curso e psicologia de uma universidade federal do sul do país, distribuídos em: 01 estagiário de último ano, 04 estagiários de quarto ano, 07 estagiários do segundo ano e 03 do primeiro ano.

Utilizaram-se dois instrumentos na coleta de dados: 1) registro das discussões resultantes das reuniões de supervisão, organizadas como grupos de discussão; 2) material produzido pelos estagiários (relatórios, comunicações eletrônicas do grupo de e-mails, material de divulgação, etc., assim como

O registro das discussões resultantes das reuniões de supervisão se constitui no encontro da complexidade humana, do encontro das verticalidades portadas por cada um com a horizontalidade do aqui e agora da reunião.

O material produzido pelos estagiários provém das atividades de planejamento, divulgação e condução das oficinas. Os relatórios podem ser considerados o material mais importante, pois trazem toda a riqueza de suas percepções, alia-se ao fato de que foram orientados a confeccionarem estes relatórios de forma a incluir suas percepções, seus sentimentos. 
Do ponto de vista dos procedimentos técnicos a pesquisa apresenta características que se aproximam da pesquisa-ação e da pesquisa-participante (GIL, 1999). Há características de pesquisa-ação por ser concebida e realizada democraticamente em associação com uma ação e a busca de resolução de um problema coletivo. Os pesquisadores e participantes estão envolvidos de modo cooperativo ou participativo. Tal formatação do estágio e da supervisão justificam os quesitos ontológicos, epistemológico e de método que sustentam a investigação.

Posto desta forma, a atividade principal da pesquisa se dá sobre as reuniões de supervisão com o grupo de estagiários, que se estruturam como grupos de discussão, em sintonia com o modo de condução dos grupos que compõem o estágio. Callejo (2001) desenha o grupo de discussão como uma via para conhecer, não como uma finalidade. É um dispositivo analisador cujo processo de produção é colocar em confronto diferentes discursos e cujo produto é a manifestação dos efeitos desse confronto (discussão) nos discursos pessoais (convencimento: convencido é aquele que foi vencido pelo grupo) e nos discursos grupais (consenso) (CALLEJO, 2001).

O método de análise do material consiste em confrontar categorias surgidas do quadro teórico e estabelecidas previamente com categorias emanadas do material empírico (SELLTIZ et al., 1975). Trabalhar com categorias surgidas previamente requer alguma diferenciação (MINAYO, 2004, p. 70), as categorias surgidas dos dados coletados são mais especificas, estas, por sua vez, devem ser confrontadas com as categorias definidas a priori.

\section{Resultados}

A partir dos dados coletados emergiram temáticas específicas em torno das grandes categorias, Inserção e Ascensão Social, Identidade e Educação, as temáticas são as seguintes: subir na vida, mercado de trabalho, trabalho e estudo e independência financeira, títulos estes retirados das falas dos estagiários.

\section{Subir na vida}

A temática sobre inserção e ascensão social não foi diretamente provocada nas oficinas, ao contrário do assunto identidade, que contou com atividades específicas, contudo, aparece naturalmente ao longo dos encontros. Na cidade de onde se desenvolveu a atividade chama a atenção a emigração como forma de inserção e ascensão social:

Então surgiu a questão de "subir na vida", pois uma outra menina ressaltou que até teria onde trabalhar em Jaguari, mas não teria futuro, pois não teria 
possibilidade de crescer no trabalho - ela disse que teria que ser possível sempre estar estudando para "subir, subir, subir" (Jaguari, Ensino Médio, Firmina $^{2}$ ).

A saída da cidade, no caso dos alunos de Jaguari, é vista ainda como uma via de mobilidade social, "subir, subir, subir" traz em si deixar o local, deixar a família, implicando uma readequação nas relações, muitas vezes antecipada nas suas dificuldades:

Todos mencionaram o desejo de ir a uma outra cidade para trabalhar, já que ali em Jaguari e, ainda mais, morando na área rural não viam muitas perspectivas de futuro. Eles mencionaram sobre o quanto é difícil passar no vestibular da UFSM, mas que iriam tentar estudando bastante (Jaguari, Ensino Médio, Pilar).

A ideia de "subir, subir" é a melhor tradução da ascensão social, e se mostra bastante inculcada nos alunos. Remete à trajetórias possíveis de inserção e ascensão social, mas de igual modo podem simplesmente ser almejadas ou oferecidas pelo sistema educacional, mas sem compromisso de que sejam cumpridas pelos alunos.

\section{Diploma e Mercado de trabalho}

O trabalho é uma preocupação bastante presente nos alunos de ensino médio de ambas as escolas e surge como um imperativo, as dúvidas e incertezas em relação ao trabalho se concentram em conseguir um emprego do qual possam retirar o sustento. No caso do escola técnica a preocupação se dá também em torno da escolha entre a profissão de técnico ou o curso superior:

Isso surgiu porque se formando no técnico já existente uma profissão podendo trabalhar $e$, assim, ganhar dinheiro. $O$ dinheiro e o próprio sustento surgiram também nas dúvidas sobre o depois da faculdade, já que esta não garante que serão bem-sucedidos (ESCOLA TÉCNICA, Firmina).

A promessa de mobilidade que a universidade traz já é vista com desconfiança por esta geração. Pode-se supor que o aumento exponencial de vagas no ensino superior diminui a distinção que se erigia entre portadores e não portadores de diploma, a inflação de diplomas inevitavelmente gera sua desvalorização (BOURDIEU, 2007). O aluno passa a observar cada vez mais cedo o mercado de trabalho, buscando a possibilidade de ascensão social dentro da distinção que o diploma ainda traz; e em determinadas situações busca "assegurar

\footnotetext{
2 Todos os nomes citados são fictícios.
} 
formalmente uma competência especifica (por exemplo, um diploma de engenheiro)" (BOURDIEU, 2007, p. 28). A garantia do diploma existiria ainda naquelas grandes universidades ou nas profissões ditas boas, ou de maior prestígio, com maior procura ou maior salário (VAUTERO et al., 2017). Essa última expressão designa aquelas profissões consideradas como de melhor retorno financeiro e prestígio social, mas ainda muito ligada à idéia de universidade:

Nós então perguntamos sobre outras profissões que teriam na sua família, irmãos, tios... Nesse momento ela só nos responde as profissões que seriam acadêmicas - uma tia fez química, outras tias eram professoras... Nós então apontamos pra ela que ela só tinha dito as profissões acadêmicas, e ela nos diz que foi isso que pedimos - cursos de faculdade, mas nós reforçamos que falamos apenas em profissões, não em faculdade. Isso foi bem interessante, pois mostra como é a representação de que as profissões que "valem", poderíamos dizer, são aquelas que passam pela faculdade (ESCOLA TÉCNICA, Amaranta).

O curso superior não é a única opção, e em alguns casos o aluno consegue vislumbrar que pode optar por outras trajetórias, mas sempre retorna a conversa sobre a raridade do diploma:

Esse fato parece pesar bastante, tendo uma menina até falado que a faculdade poderia ser uma perda de tempo, já que teria a opção de trabalhar e já ganhar dinheiro. Estava bastante presente a preocupação com o mercado de trabalho, tanto no depois do colégio quanto no depois da faculdade. Uma fala que se apresentou várias vezes foi a de que não escolheriam determinada profissão por que já existiam muitas pessoas formadas naquela profissão (ESCOLA TÉCNICA, Firmina).

O curso a ser escolhido é pensado juntamente com o mercado de trabalho, justamente dentro da ideia de buscar a mobilidade social entre as gerações (GONÇALVES; SILVEIRA NETO, 2013). Parece que os contornos individuais se esvaem à medida que o aluno se aproxima da escolha do curso universitário, como se a identidade do aluno fosse se desenhando pelo vetor mercado de trabalho. A inserção e ascensão social, ou simplesmente de manutenção, pensada enquanto algo buscado pelo aluno passa a ser imperativo social:

Essa menina disse que já tem por opção cursar arquitetura, mas que ainda não tem certeza por não saber ao certo quais as possibilidades do mercado de trabalho para a profissão (ESCOLA TÉCNICA, Martina).

Ruim com diploma, pior sem ele, o acesso universal à educação aumenta o acesso ao ensino superior, o que por sua vez diminui sua raridade (BOURDIEU, 2007), mas se mantém 
como possibilidade de acesso a uma série de postos de emprego com melhor remuneração (IBGE, 2016).

\section{Trabalho e estudo}

Trabalhar e estudar surge naquelas situações onde é necessária a mão de obra do aluno na manutenção da família:

Pergunto se mais alguns deles haviam trabalhado e a maioria responde que sim. Os que estudam na escola rural [...] mencionaram já terem trabalhado com fumo e que acabaram desistindo desse trabalho pelo fato de o veneno trazer males à saúde. (Jaguari, Ensino Fundamental, Pilar).

Petrônio destacou já ter trabalhado como servente em construções, e que com o dinheiro que recebia acabava pagando as contas de água e luz da casa. Olimpia e Gil nunca trabalharam, mas trouxeram o desejo de terem uma independência financeira dos pais, pois gostariam de não precisar pedir dinheiro para eles a cada vez que precisam de alguma coisa (Jaguari, Ensino Fundamental, Pilar).

A fala do aluno apreendida por Pilar traz a realidade do aluno que trabalha para colaborar no sustenta da família. Sobre essa realidade, observa-se que parte considerável da população jovem trabalha e estudam, em média $14 \%$ dos jovens com idades entre 15 e 17 (IBGE, 2016). Esse dado, contudo, considera apenas o trabalho formal, mas muitos trabalham junto a suas famílias, o que dificilmente é contabilizado.

Entretanto, no aluno que trabalha está embutida uma perspectiva de determinado grupo ou família; que reconhece como sendo trabalho apenas aquele semelhante ao que a própria família ou grupo desempenha, em alguns casos desvalorizando o estudo formal. Relembrado o habitus da classe de Bourdieu, pode ser uma estratégia protetiva da classe e de valorização aos moldes da raposa e as uvas, que é inculcada nos adolescentes, mesmo que muitos sejam estudantes:

Juvenal menciona que parou de estudar muito cedo por ter que trabalhar e que retomou os estudos após ter passado por uma cirurgia de tiróide que o impossibilitou de exercer o trabalho pesando. Com isso, ele traz o fato de seu pai considerar o estudo uma "perda de tempo", mas destacando receber o apoio de sua mãe para seguir em frente (Jaguari, Ensino Médio, Pilar).

Está descrito um modo de trabalho típico de regiões onde predominam pequenas propriedades rurais, não há formalidade no emprego, mas o aluno assume uma função importante da economia familiar, trabalhando na propriedade da família ou de vizinhos: Os 
meninos responderam que começaram por volta dos 10 anos, ajudando "de leve" $e$ aumentando as atividades conforme cresciam (Jaguari, Ensino Fundamental, Úrsula).

Além da necessidade da mão de obra dos filhos, as famílias parecem fazer aí também uma iniciação, na busca de manutenção do status social da família, no caso das falas trata-se em geral de trabalho rural desenvolvido em pequenas propriedades, a partir do que se pode esperar que exista grande peso dessa trajetória familiar sobre as decisões futuro desse adolescente.

\section{Dinheiro e Independência financeira}

Como também era de se esperar, o capital econômico e os ganhos reais possíveis com o investimento educacional são de interesse de todos alunos. As diferenças entre as cidades se mostram, o aluno de Jaguari discute mais a questão do dinheiro enquanto necessidade, e vinculada quase sempre à melhora da qualidade de vida:

A maioria disse que queria ter dinheiro suficiente pra viver bem, pra poder comprar as coisas que queriam, para poder dar uma condição de vida melhor pra família. Uma menina disse que dinheiro não compra a felicidade, mas ajuda a se viver melhor (Jaguari, Ensino Médio, Firmina).

Porém, juntamente com a temática dinheiro, advindo sobretudo de suas profissões futuras, surgiu o tema independência financeira: Já a menina seguinte, a partir de sua fala, trouxe um tema que ressoou nas demais participantes [...] me chamou a atenção a grande importância que essa participante em especial deu a essa meta (ESCOLA TÉCNICA, Aureliano).

Erikson (1998) propõe que na fase crítica para a identidade, vivida durante a adolescência como identidade x confusão de identidade, Havighurst (1953, apud EIZIRIK, 2001) propõe o cumprimento de algumas tarefas evolutivas no desenvolvimento do jovem adulto, a separação psicológico dos pais e cuidadores é um dos itens principais, juntamente com a definição de uma identidade ocupacional, carrega a necessidade de ganhos financeiros.

\section{Considerações finais}

A conclusão é composta de alguns questionamentos em torno que qual é o foco da educação, e que papel ela passa a desempenhar e sobre que papel a educação desempenho na construção de identidades, o que se espera do aluno, que perspectivas ela cria. 
Sobre qual é o foco e o papel da educação, entre os alunos da cidade de Jaguari, podese observar que existe uma tendência a entender a universidade como um fim natural ao seu projeto identitário. Todas as discussões trazidas pelos estagiários envolvem a universidade como um objetivo, fato que não deve causar espanto, uma vez que as oficinas de identidade na adolescência se propõem a trabalhar com as possibilidades de inserção e ascensão social na universidade. Mas existe entre os estudantes uma tendência a considerar este caminho muito mais como uma rejeição à vida citadina do interior, há um mundo visualizado através das janelas cada vez mais verossimilhantes, com destaque especial para a Internet, a qual parece que todos têm algum acesso. A educação ainda representa um projeto de inserção e ascensão social ao aluno que vê na educação superior uma possibilidade de viver um projeto de vida ainda idealizado (DUBAR, 1997, 1998).

Assim, a educação cria expectativas de que um projeto inteiro de vida se concretiza através dela, passando quase sempre pelo ensino superior, salvo alguns casos de alunos da escola técnica que também frequentavam o ensino profissionalizante. Mas obviamente, o projeto educacional não é suficiente para colocar o aluno dentro do projeto que vai construindo; mas nesse momento, apenas é possível concluir que para os alunos e estagiários, envolvidos nas oficinas de identidade, o ensino superior é um objetivo e uma via para subir na vida, sair da cidade, no caso dos alunos da cidade de Jaguari. Também é um modo de buscar a independência, autonomia, e realizar sonhos.

Quanto ao papel da educação na construção identitária segue o raciocínio e torno dos elementos que alimentam estas identidades em formação. É possível analisar o caso dentro das próprias oficinas de identidade. $\mathrm{O}$ condutor dos grupos é um estagiário vindo de uma universidade, habitante de um centro regional, isto representa um foco de identificações por parte dos alunos participantes dos grupos. No caso da cidade de Jaguari, os elementos da cultura local são vividos pelos alunos no cotidiano, em seus caminhos diários, escola, igreja, centro, campo; mas a universidade os afasta. A identidade que desenvolve dentro do seu socioambiente não é a identidade que a universidade irá considerar, a distinção está na separação a estes elementos (BOURDIEU, 2007). Subsequentemente, a identidade de universitário pressupõe a rejeição em parte da identidade que se desenvolve dentro do socioambiente originário do aluno. Algo de políticas de identidade pode estar expresso aqui; tomando a definição de Pescatore Alves, que considera o termo "como as estratégias de grupos hegemônicos, tradicionais ou emergentes; e, instâncias públicas ou privadas, na proposição de ações que objetivem atuar como mediadoras na formação identitária dos indivíduos" (ALVES et al., 2007, p. 153). 
Onde identidades são produzidas dentro de uma tradição histórica e política, e a própria sociedade elege aqueles elementos que constituem determinada identidade, rejeitando características que não considera inerentes. Parece que quando se falava dos represamentos que se formavam na identidade, estava se falando de políticas de identidade que se constroem sobre a figura do estudante.

\section{REFERÊNCIAS}

ALVES, C. P.; SOUZA, R. T.; SILVA, A. L.; PIMENTA, C. A. M. Na trilha da identidade cultural: apontamentos teórico-metodológicos em pesquisa de políticas públicas culturais e educacionais. Revista Brasileira de Gestão e Desenvolvimento Regional, Taubaté, v. 3, p. 149-169, 2007. Disponível em:

http://www.rbgdr.net/revista/index.php/rbgdr/article/view/111. Acesso em: 23 nov. 2018.

BARDIN, L. Análise do Conteúdo. 3. ed. Lisboa: Edições 70, 2004.

BLAU, P. M.; DUNCAN, O. D. The American Ocupational Strutucture. New York: John Wiley \& Sons, 1967.

BOURDIEU, P.; PASSERON, J. C. A reprodução: elementos para uma teoria do sistema de ensino. 3. ed. Rio de Janeiro: Franciso Alves, 1992.

BOURDIEU, P. A distinção: Crítica Social do Julgamento. São Paulo: Edusp, 2007.

CALLEJO, J. El grupo de discusión: introducción a una práctica de investigación.

Barcelona: Editorial Ariel, 2001.

D'AVILA, J. L. P. Trajetória escolar: Investimento familiar e determinação de classe. Educ. Soc., Campinas, v. 19, n. 62, Abr. 1998. Disponível em: http://www.scielo.br/scielo.php?scri pt=sci_arttext\&pid=S0101-73301998000100003\&lng=en\&nrm=iso. Acesso em: 22 nov. 2018.

DUBAR, C. A socialização: construção das identidades sociais e profissionais. Porto: ed. Porto, 1997.

DUBAR, C. Trajetórias sociais e formas identitárias: alguns esclarecimentos conceituais e metodológicos. Educ. Soc., Campinas, v. 19, n. 62, Abr. 1998 . Disponível em:

http://www.scielo.br/scielo.php?script=sci_arttext\&pid=S0101-

$73301998000100002 \& \operatorname{lng}=e n \& n r m=$ iso. Acesso em: 13 dez. 2018.

GONCALVES, M. B. C.; SILVEIRA NETO, R. M. Persistência intergeracional de educação no Brasil: o caso da Região Metropolitana do Recife. Estud. Econ., São Paulo, v. 43, n. 3, p. 435-463, sept. 2013. Disponível em:

http://www.scielo.br/scielo.php?script=sci_arttext\&pid=S0101-

$41612013000300001 \& \operatorname{lng}=e n \& n r m=i s o$. Acesso em: 22 jan. 2019.

ERIKSON, E. H. Identidade, juventude e crise. Rio de Janeiro: Zahar Editores, 1976. 
GIL, A. C. Métodos e técnicas de pesquisa social. São Paulo: Atlas, 1999

IBGE - INSTITUTO BRASILEIRO DE GEOGRAFIA E ESTATÍSTICA. Desemprego volta a crescer no primeiro trimestre de 2018. Disponível em :

https://agenciadenoticias.ibge.gov.br/agencia-noticias/2012-agencia-de-

noticias/noticias/20995-desemprego-volta-a-crescer-no-primeiro-trimestre-de-2018. Acesso em: 11 jan. 2019b.

\section{IBGE - INSTITUTO BRASILEIRO DE GEOGRAFIA E ESTATÍSTICA. Síntese de}

Indicadores Sociais: indicadores apontam aumento da pobreza entre 2016 e 2017. Disponível em: https://agenciadenoticias.ibge.gov.br/agencia-sala-de-imprensa/2013-agencia-denoticias/releases/23298-sintese-de-indicadores-sociais-indicadores-apontam-aumento-dapobreza-entre-2016-e-2017. Acesso em: 18 jan. 2019.

IBGE - INSTITUTO BRASILEIRO DE GEOGRAFIA E ESTATÍSTICA. Síntese de indicadores sociais. Uma análise das condições de vida da população brasileira: 2016. Disponível em: https://biblioteca.ibge.gov.br/visualizacao/livros/liv98965.pdf. Acesso em: 20 nov. 2018.

INEP - Instituto Nacional de Estudos e Pesquisas Educacionais Anísio Teixeira. Censo Escolar da Educação Superior 2016. Brasília, DF: Ministério da Educação. Disponível em: http://portal.inep.gov.br/informacao-da-publicacao//asset_publisher/6JYIsGMAMkW1/document/id/1473851. Acesso em: 19 nov. 2018.

LEMOS, A. E. C.; DUBEUX, V. J. C.; PINTO, M. C. S. Educação, empregabilidade e mobilidade social: convergências e divergências. Cad. EBAPE.BR, Rio de Janeiro, v. 7, n. 2, p. 368-384, jun. 2009. Disponível em:

http://www.scielo.br/scielo.php?script=sci_arttext\&pid=S1679-

39512009000200012\&lng=en\&nrm=iso. Acesso em: 18 jan. 2019.

LIPSET, S. M.; BENDIX, R. Social mobility in industrial society. Berkeley: The University of California Press, 1959.

MEAD. G. H. Espiritú, persona y sociedad: desde el punto de vista del conductivismo social. 3. ed. Buenos Aires: Paidós, 1972.

MINAYO, M. C. S. Pesquisa Social: Teoria, método e criatividade. 23. ed. Petrópolis: Vozes, 2004.

NOGUEIRA, C. M. M.; NOGUEIRA, M. A. A sociologia da educação de Pierre Bourdieu: limites e contribuições. Educação e Sociedade, Campinas, v. 23, n. 78, abr. 2002. p. 15-36. Disponível em: http://www.scielo.br/scielo.php?pid=S0101-

73302002000200003\&script=sci_abstract\&tlng=pt. Acesso em: 23 nov. 2018.

PASTORE, J.; SILVA. N. V. Mobilidade Social no Brasil. São Paulo: Makron Books, 2000.

PASTORE, J.; HALLER, A. O. O que está acontecendo com a mobilidade social no Brasil? In: VELOSO. J. P. R.; ALBUQUERQUE, R. C. A. (org.) Pobreza e mobilidade social. São Paulo: Nobel, 1993. p. 25-49. 
SANTOS, B. S. A universidade no século XXI: para uma reforma democrática e emancipatória da universidade. 2. ed. São Paulo: Cortez, 2005.

SCHULTZ, T. O Valor econômico da educação. 2. ed. Rio de Janeiro: Zahar, 1973.

SELLTIZ. C. et al. Métodos de pesquisa nas relações sociais. São Paulo: Edusp,1975.

STRAUSS, A. Espelhos e máscaras. São Paulo: Edusp, 1999.

VAUTERO, J. R. et al. Influência da escolaridade dos pais no prestígio do curso universitário escolhido pelos filhos. PSICOLOGIA, Lisboa, v. 31, n. 2, p. 155-158., nov. 2017.

Disponível em: https://www.infona.pl/resource/bwmeta1.element.springer-doi-10_1007S12564-015-9395-4. Acesso em: 18 de nov. 2017.

\section{Como referenciar este artigo}

VAUTERO, Jaisso. Oficinas de identidade na adolescência. Doxa: Rev. Bras. Psico. e Educ., Araraquara, v. 21, n. 1, p. 62-77, jan./jun. 2019. e-ISSN: 2594-8385. DOI: https://doi.org/10.30715/doxa.v21i1.12096

Submetido em: 10/10/2018

Revisões requeridas: 30/10/2018

Aprovado em: 20/11/2018

Publicado em: 01/02/2019 